\title{
Simulation and Implementation of $\Gamma$-Z Source Inverter
}

\author{
G.V.Sreekanth Reddy*, J.N.Chandrasekhar** \\ *(M.Tech, Department of EEE, Sri Venkateswara university College of Engineering, Tirupati \\ **(Assistant Professor, Department of EEE,Sri Venkateswara university College of Engineering, Tirupati
}

\begin{abstract}
This venture "Simulation and Implementation of $\Gamma$-Z-Source Inverters" is made out of Voltage-sort $\Gamma$-Z source inverters are proposed in this letter. They utilize a remarkable $\Gamma$-molded impedance arrange for boosting their yield voltage notwithstanding their standard voltage buck conduct. Contrasting them and different topologies, the proposed inverters utilize lesser parts and a coupled transformer for delivering the high-pick up and regulation proportion all the while. The got pick up can be tuned by changing the turns proportion $\gamma \Gamma Z$ of the transformer inside the limited scope of $1 \& \mathrm{lt} ; \gamma \Gamma Z \leq 2$. This prompts to lesser twisting turns at high pick up, as compared to other related topologies.
\end{abstract}

Keywords - Embedded-Z-source, quasi-Z-source, T-source, Trans-Z-source, Z-source, $\Gamma$-Z-source inverters.

\section{INTRODUCTION}

Advanced power electronic applications, particularly those specifically associated with the framework, normally require some voltage boosting. Customary voltage-source inverters (VSIs) are along these lines not palatable since they can just stride down voltages. To include support us efulness, dc-dc help converters can be put before the VSIs. Then again, single-stage buck-support inverters can be utilized like the Cuk, SEPIC, and other comparative $\mathrm{dc}-\mathrm{ac}$ inverters found in [1] and [2]. These inverters however don't have escalated follow-up research. Despite what might be expected, explore in another buck-help inverter, named as the Z-source inverter [3], has developed quickly with its balance, dynamics, control, and measuring considered in [4][7]. Its applications to engine drives [8], sunlight based era [9], and electric vehicles [10] have additionally been endeavored utilizing a similar fundamental Z-source impedance organize found in [3].Changes to the essential system just surface in [11]-[14], where their separate upgraded systems are named as improved,quasi-, and inserted Z-source systems. In spite of the fact that named in an unexpected way, these systems are firmly comparable with [15] clarifying that they contrast just in their source positions. The three systems can in the long run be converged into a solitary non specific system without any progressions acquainted with the quantity of LC components

\section{Z-Source and Trans-Z-Source Inverters}

The main Z-source inverter proposed in [3] is appeared in Fig. 1, where a one of a kind Xmolded impedance system can obviously be seen. This additional system permits changes from a similar stage leg to be turned $\mathrm{ON}$ all the while without bringing on damages. Instead, the shootthrough state made causes the inverter yield to be helped without twisting on the off chance that it is utilized legitimately with the other eight Nonshootthrough dynamic and invalid states. The subsequent expressions for figuring the system capacitor voltage $\mathrm{VC}$, crest dc-connect voltage $\hat{\mathrm{v}^{\wedge}}$ amid the Nonshoot-through state, and top air conditioning yield voltage v^ac can accordingly be determined and

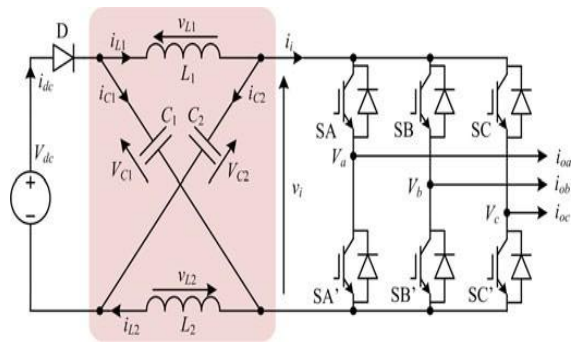

Fig. 1. Traditional Z-source inverter.

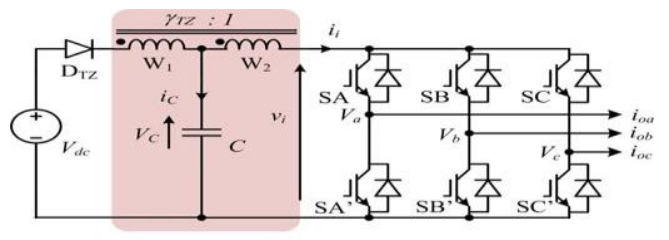

(a)

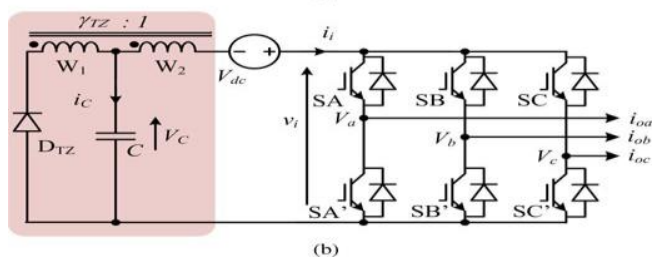

Fig. 2. Trans-Z-source inverters with source placed in series with (a) diode or(b) VSI bridge written in the following equation:

$$
\begin{aligned}
& V_{C}=\frac{1-d_{S T}}{1-2 d_{S T}} V_{d e} ; V_{i}=\frac{1}{1-2 d_{S T}} V_{d e} \\
& v_{a c}=M \frac{V_{i}}{2}=\frac{1}{1-2 d_{S T}}\left(0.5 M V_{d e}\right)
\end{aligned}
$$


Where $V_{\mathrm{dc}}, M$, and $d \mathrm{ST}$ represent the input voltage, modulation ratio, and fractional shoot-through time, respectively.

The boost factor from (1) is hence expressed as $\mathrm{B}=1 Z /(1-2 d \mathrm{ST})$. Setting its denominator to be greater than zero then results in the operating range of $0 \leq d \mathrm{ST}<0.5$.

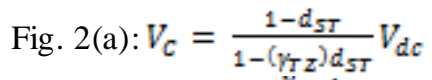

$$
\begin{aligned}
& \text { Fig. 2(b): } V_{C}=\frac{\gamma_{T Z d_{S T}}}{1-\left(_{T I}+1\right) d_{S I}} V_{d c} \\
& v_{i}=\frac{1}{1-\left(h_{T I}+1\right) d_{S T}} V_{d e} \\
& v_{a c}=\frac{1}{1-\left(\mathrm{Frz}_{\mathrm{T}}+1\right) d_{S I}}\left(0.5 M V_{d c}\right)
\end{aligned}
$$

Since the shoot-through state must be set inside an invalid interim to abstain from presenting volt-sec blunder, relationship amongst $\mathrm{M}$ and $\mathrm{d}_{\mathrm{ST}}$ can further be composed as $\mathrm{M} \leq 1.15\left(1-\mathrm{d}_{\mathrm{ST}}\right)$. To deliver a high-voltage support, $M$ should henceforth be brought down.

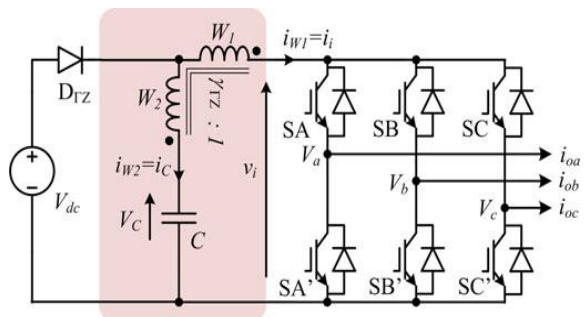

(a)

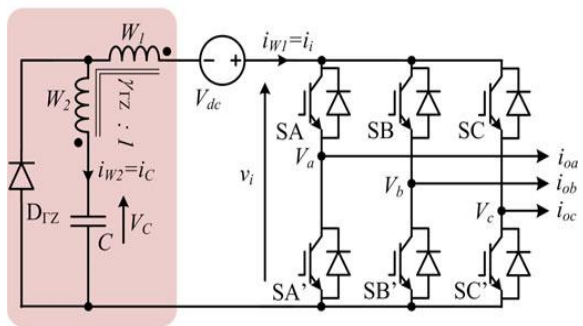

(b)

Fig. 3. $\Gamma$-Z-source inverters with source placed in series with (a) diode or (b) VSI bridge.

Bring down $\mathrm{M}$ how-ever prompts to highvoltage worries over the segments and poor unearthly exhibitions. To keep away from these limitations, T-source or trans-Z-source inverters are proposed [19], [20]. In like manner, the trans-Zsource inverters appeared in Fig. 2 utilize just a single trans-previous with turns proportion $\gamma \mathrm{TZ}=$ W1/W2 and one capacitor. They contrast just in their source situations, whose impact is to differ VC yet not alternate voltages. This can unmistakably be seen from (2), where expressions for processing VC , $\mathrm{v}^{\wedge} \mathrm{i}$, and $\mathrm{v}^{\wedge}$ ac for the trans-Z-source inverters are introduced [20]

Comparing the denominators of (1) and (2), it is clear that the trans-Z-source gain can be raised above the traditional Z-source gain if $\gamma \mathrm{TZ}$ is set greater than one $(\gamma \mathrm{TZ} \geq 1)$. From (2), the new limits for $d$ ST can also be determined as $0 \leq d \mathrm{ST}$ $<1 /(\gamma \mathrm{TZ}+1)$, after setting the denominator of (2) to be greater than zero. Clearly, the upper limit of $d \mathrm{ST}$ can be reduced by using a higher $\gamma \mathrm{TZ}$ for gain boosting. The lower $d \mathrm{ST}$ then leads to a higher modulation ratio since $M \leq 1.15(1-d \mathrm{ST})$.

\section{T-Z-SOURCE INVERTERS}

For the trans-Z-source inverters, high pick up is gotten by expanding their regular transformer turns proportion $\gamma_{\mathrm{TZ}}$, which is in concurrence with established transformer hypotheses. Contingent upon the inevitable voltage pick up requested, the raised $\gamma_{\mathrm{TZ}}$ may on occasion be over the top for acknowledgment. On account of this, $\Gamma$-Z-source inverters attracted Fig. 3 are proposed in this letter as alternatives. The proposed inverters utilize an indistinguishable parts from the trans-Z-source inverters, however with various transformer situation. This distinction causes the $\Gamma$-Z-source pick up to be raised by lowering, and not expanding, the transformer turns proportion $\gamma_{\Gamma Z}$. Scope of $\gamma_{\Gamma Z}$ can in reality be resolved as $1<\gamma_{\Gamma Z} \leq 2$, as showed in the accompanying segment

\section{A. Steady-State Expressions}

Shoot-Through State: framed by turning ON two changes from a similar stage leg at the same time to short the dc-interface voltage vi to zero. In the meantime, input diode $\mathrm{D} \mathrm{Z}$ blocks, hence offering ascend to the equal circuit appeared in Fig. 4(a).Using this proportional circuit, the accompanying circuit conditions can be written:

Fig. 3(a): $V_{W 1}=V_{W 2}+V_{C} ; V_{W 1}=\gamma_{T Z} V_{W 2}: \gamma_{T Z}=\frac{W_{1}}{W_{2}}$

$$
\Rightarrow V_{W 2}=V_{C} /\left(\gamma_{T Z}-1\right) \text {. }
$$

Fig. 3(a): $V_{W 1}=V_{W 2}+V_{C}+V_{d e}: V_{W 1}=\gamma_{T Z} V_{W 2}$

$$
\Rightarrow V_{W 2}=\left(V_{C}+V_{d e}\right) /\left(\gamma_{T Z}-1\right) \text {. }
$$

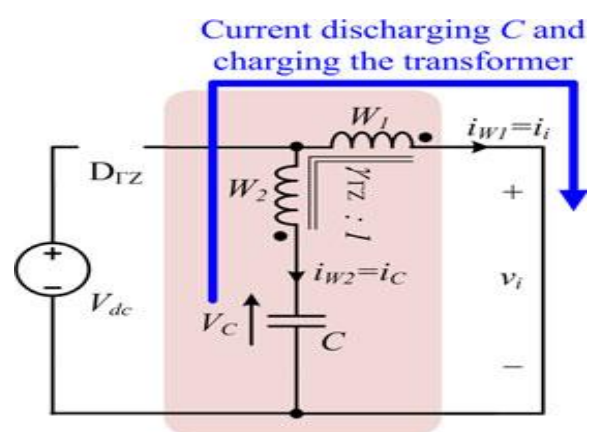

(a) 


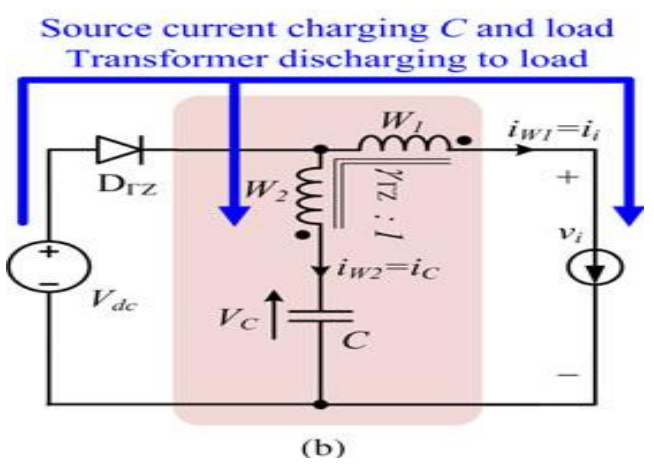

Fig. 4. Equivalent circuits of the $\Gamma$-Z-source inverter in Fig. 3(a) when in(a) shoot-through and (b) nonshoot-through states.

Nonshoot-Through State: Shoot-Through State: framed by turning ON two changes from a similar stage leg at the same time to short the dc-interface voltage $v_{i}$ to zero. In the meantime, input diode DГZ blocks, hence offering ascend to the equal circuit appeared in Fig. 4(a).Using this proportional circuit, the accompanying circuit conditions can be written:

Fig. 3(a): $V_{W 2}=V_{d e}-V_{C^{*}} V_{W 1}=\gamma_{T Z} V_{W 2}$

Fig. 3(b): $V_{W 2}=-V_{C^{\prime}} V_{W 1}=\gamma_{T Z} V_{W 2}$

Performing state-space averaging on either winding $\mathrm{W} 2$ or $\mathrm{W} 1$ then leads to the following two expressions for computing capacitor voltage $\mathrm{VC}$ :

$$
\begin{aligned}
& V_{C}=\left(1-d_{S T}\right) V_{d c} /\left(1-\left(1+\frac{1}{\gamma_{T Z}-1}\right) d_{S T}\right) \\
& V_{C}=\left(\frac{d_{S T}}{\gamma_{T Z}-1}\right) V_{d d} /\left(1-\left(1+\frac{1}{\gamma_{T Z}-1}\right) d_{S T}\right)
\end{aligned}
$$

Using (7) and (8), the peak dc-link voltage v^i during the Nonshoot-through interval and peak ac output voltage v^ac can be determined as (9) and (10) for the two inverters shown in Fig. 3

$$
\begin{aligned}
& v_{i}=V_{d e} /\left(1-\left(1+\frac{1}{\gamma_{T z}}\right) d_{S T}\right) \\
& v_{a c}=0.5 M V_{d e} /\left(1-\left(1+\frac{1}{\gamma_{T z}}\right) d_{S T}\right)
\end{aligned}
$$

These equations are closely similar to those of the trans-Z-source inverters listed in (2). They are in fact the same if their respective turn's ratios are set according to the following equation:

$$
\gamma_{T Z}=1 /\left(\gamma_{\Gamma Z}-1\right) \text { or } \gamma_{\Gamma Z}=1+1 / \gamma_{T Z}
$$

Producing a gain higher than the traditional Z-source inverter shown in Fig. 1 would hence require $\gamma \mathrm{TZ}$ to be greater than $1(\gamma \mathrm{TZ} \geq 1)$ for the trans-Z-source inverters, and $\gamma \Gamma Z$ to be reduced from 2 to 1 for the $\Gamma$-Z-source inverters $(1<\gamma \Gamma Z \leq 2)$. At high gain, $\gamma \mathrm{TZ}$ might hence be excessive $(\gamma \mathrm{TZ} \rightarrow \infty$ in the ideal case), while $\gamma \Gamma Z$ approaches 1 . The former might result in more turns for the trans-Zsource inverters especially when sufficient number of turns is needed for their low voltage W2 winding for maintaining tight coupling. The proposed $\Gamma-Z$ source inverters, on the other hand, can have their transformer wound on a core with high $\mathrm{nH} / \mathrm{t} 2$ ( $\mathrm{t}$ stands for turns) to keep their winding turns low [21]. These possibilities and ratio tuning range $(1<$ $\gamma \Gamma Z \leq 2)$ of the $\Gamma$-Z-source inverters have so far not been identified by other researchers.

\section{B. Transient Expressions}

The prior inferred expressions are for registering the inverter reactions in the enduring state. To process their transient reactions, little flag investigation exhibited in [22] is connected first to locate the nonstop capacitor voltage variety $\tilde{\mathrm{VC}}$ when bothered by an adjustment in shoot -through time D̃ ST in the Laplace space . The subsequent expression for the inverters in Fig. 3 is given as

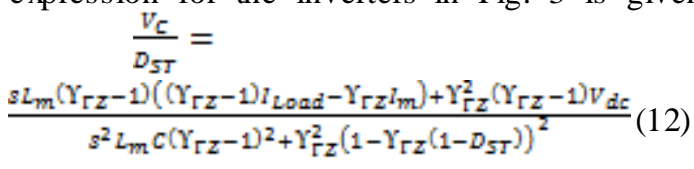

\section{DIFFER ENT APPROACHES B Y US ING DIFFER ENT CONTROLLERS}

Here various sorts of methodologies are fin ished by utilizing diverse kind of controllers .Here first the outcomes are watched for the open circle circuit which Rise time and Settling time is high,then the circuit is utilized with various controllers like PI controller and Fuzzy controller are utilized and the Output speed,voltage speed and Torque wave structures are observed.The out put aftereffects of various controllers are given underneath by utilizing distinctive controllers the change or the distinction in the execution of the frame work in various cases is seen from this we can watch that the out put is better in shut circle PI controller utilized circuit when contrasted and open circle framework. The circuit in whch we utilized FLC has great yield speed and torque comes about than PI controller

The Rise time, Settling time in various cases will give a thought regarding the execution utilizing distinctive controllers

\section{Open loop ckt T-Z-source inverter:}

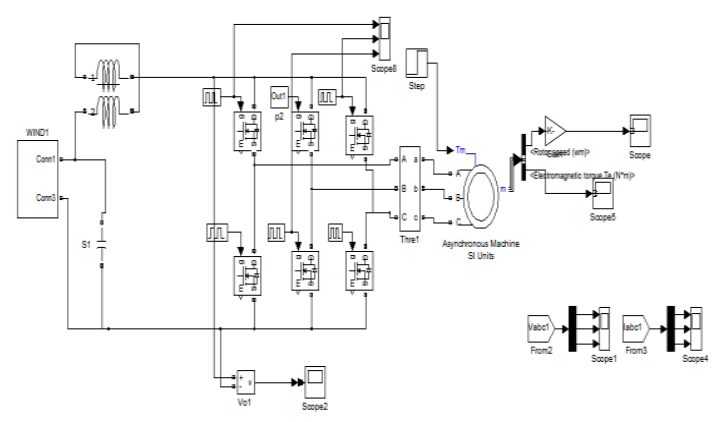



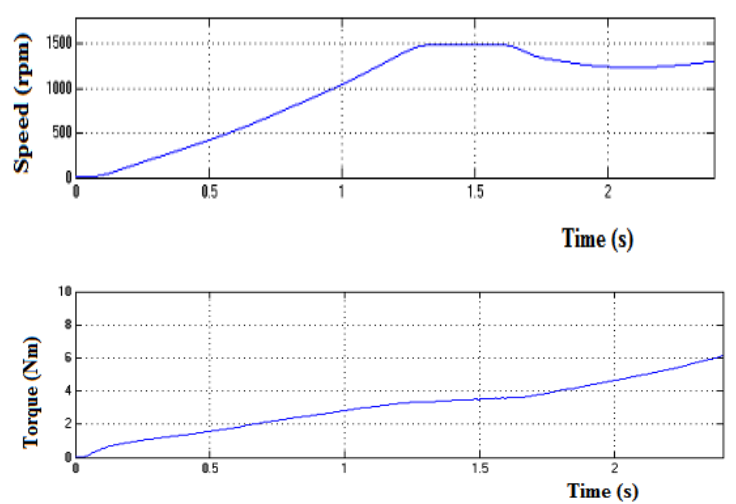

Here the above wave forms are output speed and torque wave forms of open loop system

Simulink model of the closed loop system with PI controller:
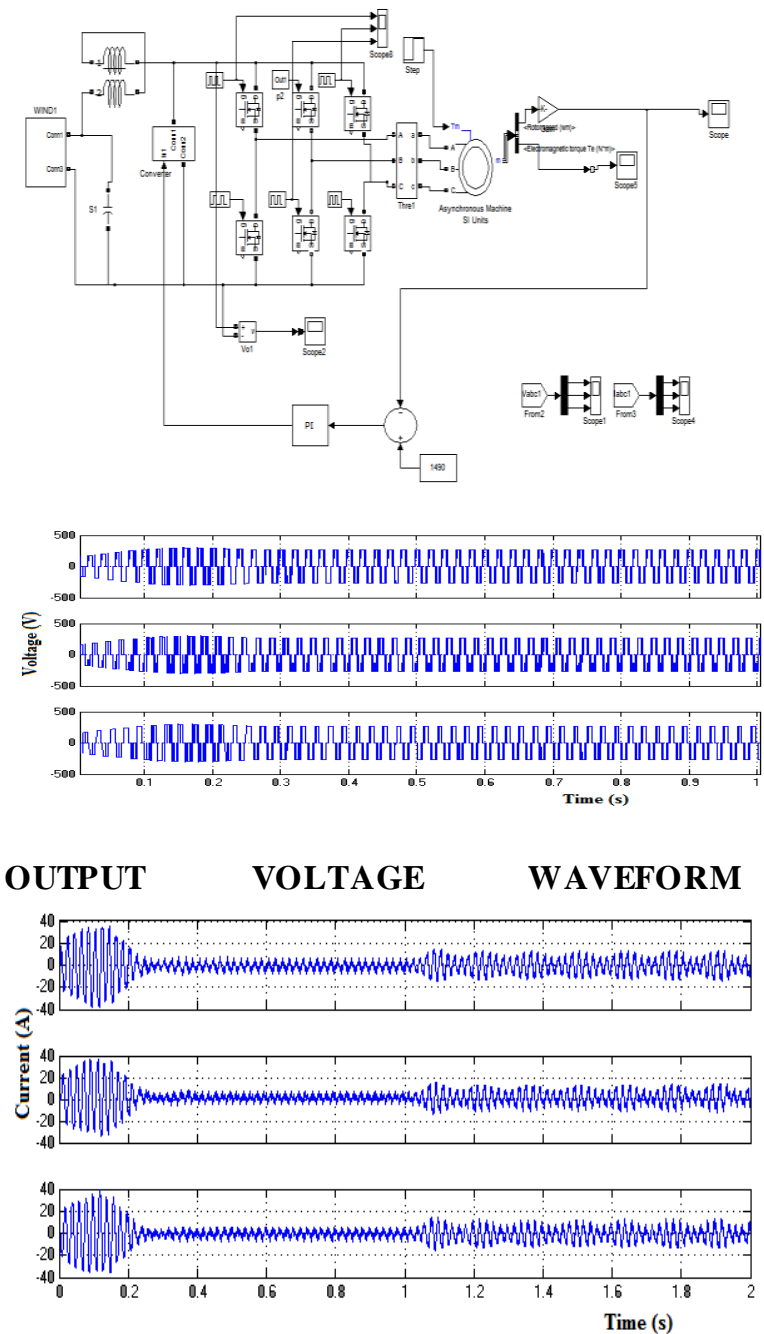

\section{OUTPUT CURRENT WAVEFORM}

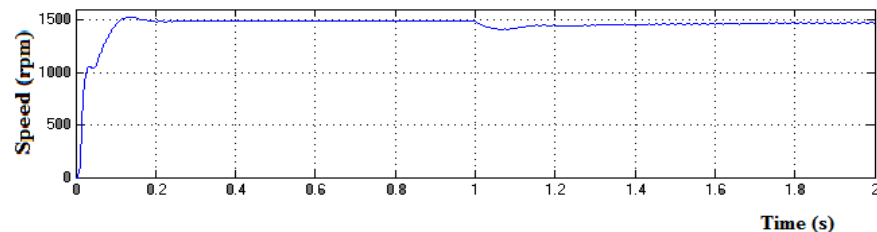

\section{SPEED WAVEFORM}

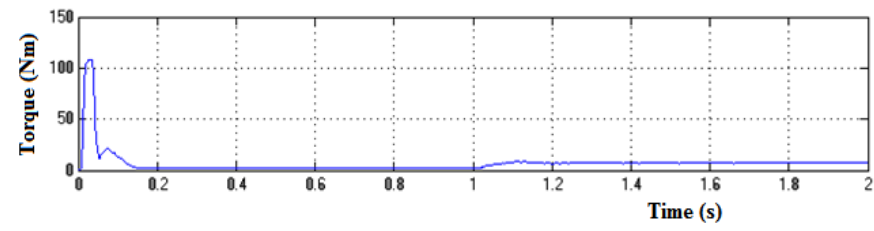

TORQUE WAVEFORM

Simulink model of the closed loop system with FLC:
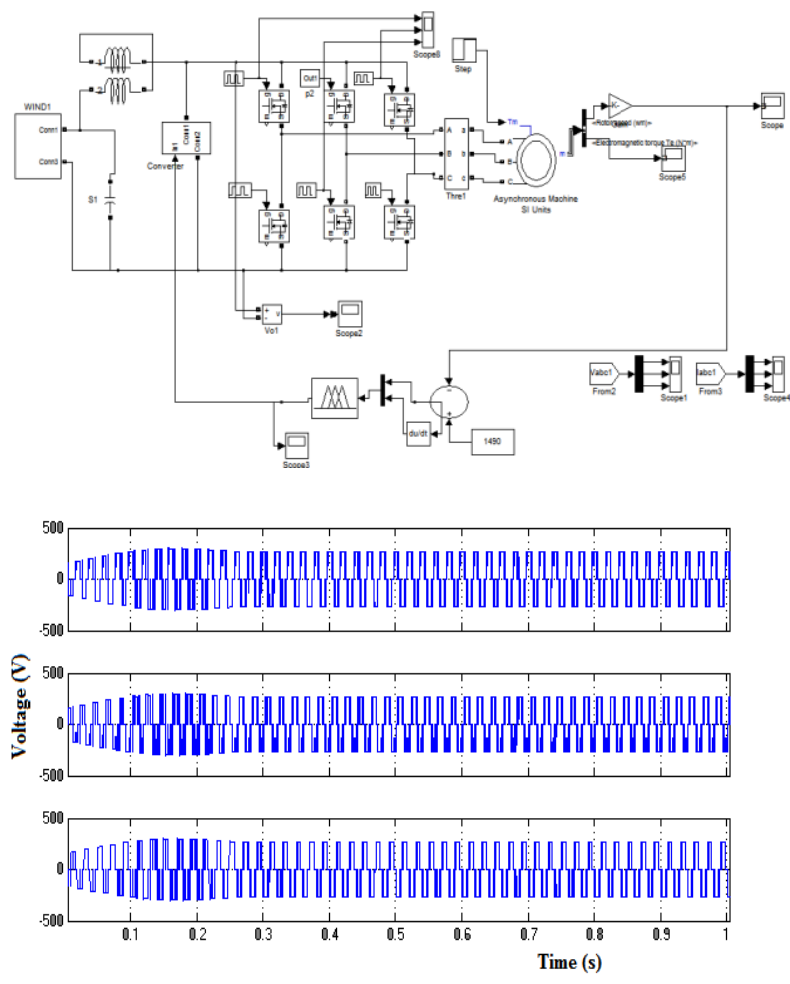

OUTPUT VOLTAGE WAVEFORM

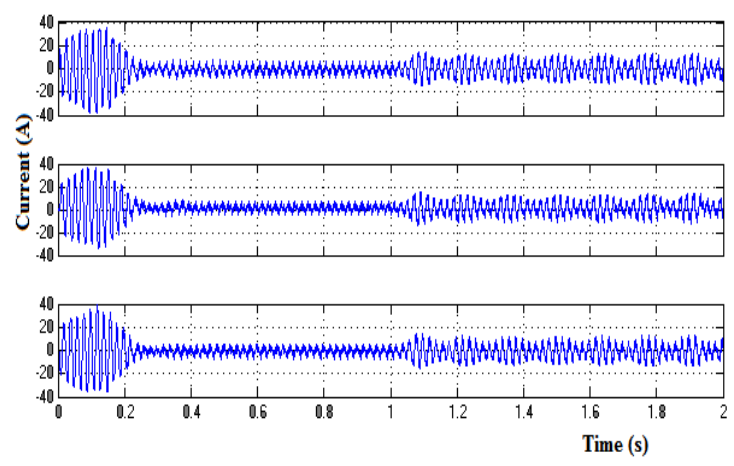

OUTPUT CURRENT WAVEFORM 


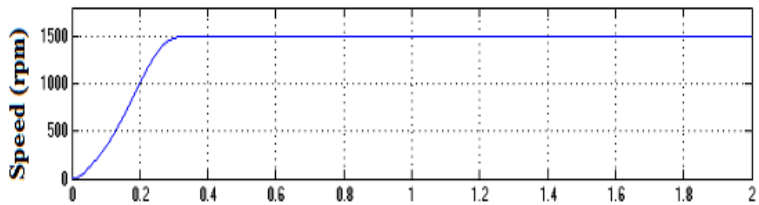

SPEED WAVEFORM

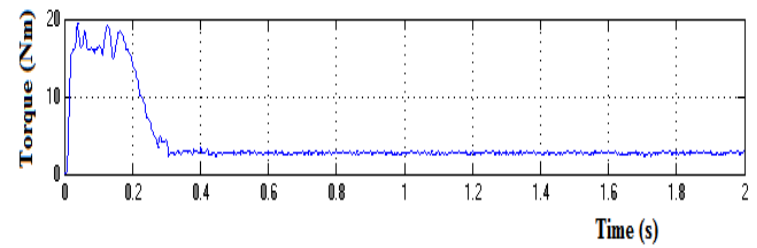

TORQUE WAVEFORM

COMPARISON TABLE

\begin{tabular}{|l|l|l|l|}
\hline Controllers & Rise Time(s) & $\begin{array}{l}\text { Settling } \\
\text { Time(s) }\end{array}$ & $\begin{array}{l}\text { Steady state } \\
\text { error(rmp) }\end{array}$ \\
\hline Open loop & 1.25 & 1.3 & - \\
\hline PI Controller & 0.3 & 0.35 & 30 \\
\hline FLC & 0.25 & 0.26 & - \\
\hline
\end{tabular}

\section{CONCLUS ION}

This venture has exhibited the methods for the limit and controller outline of the $\Gamma$-Z-Source Inverters framework. Working addition and balance proportion of the $\Gamma$-Z-source inverters have been ended up being the same as the trans-Z-source inverters, and thus higher than those of the conventional Z-source inverter. In any case, not at all like the trans-Z-source inverters, pick up increment of the $\Gamma$-Z-source inverters is accomplished by diminishing, and not expanding, their turns proportion in the scope of $1<\gamma \Gamma Z \leq 2$. Transformers required by the $\Gamma$-Z-source inverters may in this way be littler for high-pick up applications.

The Basic circuit and altered circuit components are composed utilizing applicable conditions. The reproduction circuits are created utilizing components of Simulink library. The Simulation is effectively done and open circle/shut circle with PI controller and FLC reenactment results are exhibited. The Simulation comes about agree with the hypothetical outcomes.

\section{REFERENCES}

[1] J. Kikuchi and T. A. Lipo, "Three phase PWM boostbuck rectifiers with power regenerating capability," IEEE T rans. Ind. Appl., vol. 38, no. 5,pp. 1361-1369, Sep./Oct. 2002.

[2] G. Moschopoulos and Y. Zheng, "Buck-boost type acdc single-stage converters," in Proc. IEEE Int. Symp. Ind. Electron., Jul. 2006, pp. 1123-1128.

[3] F. Z. Peng, "Z-source inverter," IEEE Trans. Ind. Appl., vol. 39, no. 2,pp. 504-510, Mar./Apr. 2003.

[4] P. C. Loh, D. M. Vilathgamuwa, Y. S. Lai, G. T Chua, and Y. W. Li,"Pulse-width modulation of Zsource inverters," IEEE Trans. Power Electron., vol. 20, no. 6, pp. 1346-1355, Nov. 2005.

[5] J. Liu, J. Hu, and L. Xu, "Dynamic modeling and analysis of Z-source converter-Derivation of ac small signal model and design-oriented analysis," IEEE Trans. Power Electron., vol. 22, no. 5, pp. 1786-1796, Sep.2007.

[6] G. Sen and M. E. Elbuluk, "Voltage and currentprogrammed modes in control of the Z-source converter," IEEE Trans. Ind. Applicat., vol. 46,no. 2, pp. 680-686, Mar./Apr. 2010.

[7] S. Rajakaruna and L. Jayawickrama, "Steady-state analysis and designing impedance net work of Z-source inverters," IEEE Trans. Ind. Electron.,vol. 57, no. 7, pp. 2483-2491, Jul. 2010.

[8] F. Z. Peng, A. Joseph, J. Wang, M. Shen, L. Chen, Z. Pan, E. Ortiz-Rivera,and Y. Huang, "Z-source inverter for motor drives," IEEE Trans. Power Electron., vol. 20, no. 4, pp. 857-863, Jul. 2005.

[9] M. Hanif, M. Basu, and K. Gaughan, "Understanding the operation of a Z-source inverter for photovoltaic application with a design example,"IET Power Electron., vol. 4, no. 3, pp. 278-287, Mar. 2011.

[10] F. Z. Peng, M. Shen, and K. Holland, "Application of Z-source inverter for traction drive of fuel cellBattery hybrid electric vehicles, IEEE Trans. Power Electron., vol. 22, no. 3, pp. 1054-1061, May 2007.

[11] Y. Tang, S. Xie, C. Zhang, and Z. Xu, "Improved Zsource inverter with reduced Z-source capacitor voltage stress and soft-start capability," IEEE Trans. Power Electron., vol. 24, no. 2, pp. 409-415, Feb. 2009.

[12] J. Anderson and F. Z. Peng, "A class of quasi-Z-source inverters," in Proc. IEEE Ind. Appl. Soc., Oct. 2008, pp. 1-7.

[13] P. C. Loh, F. Gao, and F. Blaabjerg, "Embedded EZsource inverters," IEEE Trans. Ind. Appl., vol. 46, no. 1, pp. 256-267, Jan./Feb. 2010.

[14] [14] F. Gao, P. C. Loh, F. Blaabjerg, and C. J. Gajanayake, "Operational analysis and comparative evaluation of embedded Z-Source inverters," in Proc. IEEE Power Electron. Spec. Conf., Jun. 2008, pp. 2757-2763.

[15] D. Li, F. Gao, P. C. Loh, M. Zhu, and F. Blaabjerg, "Hybrid-source impedance networks: Layouts and generalized cascading concepts," IEEE Trans. Power Electron., vol. 26, no. 7, pp. 2028-2040, Jul. 2011.

[16] M. Zhu, K. Yu, and F. L. Luo, "Switched induct or Zsource inverter," IEEE Trans. Power Electron., vol. 25, no. 8, pp. 2150-2158, Aug. 2010.

[17] M. Zhu, D. Li, P. C. Loh, and F. Blaabjerg, "T appedinductor Z-source inverters with enhanced voltage boost inversion abilities" in Proc. IEEE Int. Conf. Sustainable Energy Technol., Dec. 2010, pp. 1-6.

[18] M. Adamowicz, "LCCT -Z-source inverters," in Proc. Int. Conf. Environ. Elect. Eng., May 2011, pp. 1-6.

[19] R. Strzelecki, M. Adamowicz, N. Strzelecka, and W. Bury, "New type T-source inverter," in Proc. Compat. Power Electron.'09, May 2009, pp. 191-195.

[20] W. Qian, F. Z. Peng, and H. Cha, "Trans-Z-source inverters," IEEE Trans. Power Electron., vol. 26, no. 12, pp. 3453-3463, Dec. 2011.

[21] Selection table for Molypermalloy Powder (MPP) cores, Magnetics. (2013). [Online]. Available:http://web2.spangen.prod.bridgelinesw.net/p roduct s/powder-cores/mpp-cores

[22] P. C. Loh, D. M. Vilathgamuwa, C. J. Gajanayake, Y. R. Lim, andC. W. Teo, "Transient modeling and analysis of pulse-width modulated Z source inverter," IEEE Trans. Power Electron., vol. 22, no. 2, pp. 498507, Mar. 2007. 